\title{
THINKING ABOUT COCONUT BREEDING PROGRAMMES
}

by

\author{
Hugh C. Harries*
}

\section{INTRODUCTION}

The following text is based on coconut breeding experience in Jamaica, Thailand and Papua New Guinea, as well as on working visits to many (but by no means all) coconut growing countries. The ideas expressed are those of the author, but they have benefited from an open exchange of views with coconut breeding colleagues, research workers, extension officers, agricultural economists and others. Perhaps coconut farmers themselves have not been fully consulted, but the reason for this will be explained in the concluding section. To some extent, this article is a statement of intent concerning future coconut breeding work, particularly where serious disease and difficult growing conditions require more to be done than simply the introduction and multiplication of $\mathrm{F}$, hybrids.

The procedures for cross-pollination are not dealt with here. They are described elsewhere and those sources should be read before venturing into the field. What could be worse than to question the final results of some breeding programmes because the techniques were unreliable? However, no amount of book learning will replace climbing the palm and doing the emasculation, the bagging where necessary, the pollen collection, processing and application. Nor can the patience be taught, that is required to continue working while waiting up to six years before the next generation is ready to be pollinated. How many coconut breeding programmes have come to grief in that space of time? These difficulties cannot be entirely overcome by younger people working on younger palms because the experience of the former and the performance of the latter are undeveloped. But even when the techniques are good, the staff is trained and the work is carefully performed and closely monitored there still remains one question. Have the aims and objectives of the coconut breeding programme been thought about thoroughly and evaluated properly BEFORE the first pollination is made? That is what this paper seeks to address.

\section{GENERAL STATEMENTS ABOUT COCONUT BREEDING PROGRAMMES}

The following summary of the coconut breeding programmes in a number of different countries is made without specific reference since no criticism of any of those programmes is implied. The intention is only to illustrate the range of factors which are commonly considered to be important.

It has been suggested that the main objectives of a coconut breeding programme is to produce planting material on a large scale having desirable characteristics, such as early bearing and high yield of copra/oil per unit area. Beside these main objectives, it has been recommended that other factors should be incorporated. For instance. high oil content of copra, short palm habit, resistance to pests and disease, high lauric acid content in the oil, high content of protein in coconut meal, high yield of copra per unit area with little use of fertilizer.

\footnotetext{
${ }^{1}$ Formerly Plant Breeder, Coconut Industry Board, Jamaica and ODA Coconut Development Project, Thailand.
} 
Designated Plant Breeder, National Coconut Development Programme, P.O. Box 6226, Dar es Salaam, Tanzania.

An increase in the yield per hectare is a natural goal for improvement but, in addition, there is a place for quality criteria in the oil content, and the protein content and composition. The diversity of coconut growing regions requires new material to adapt to a range of ecological conditions and also to diseases and insect pests. Methods of selection are frequently based on identifying the combining ability of individuals from different origins. This in turn is based on phenotypic selection of characters which arc known, or suspected, to be highly heritable. Genetic variability is increased by making introductions from other countries. Imported germplasm may arrive in the form of seednuts, embryos or pollen and entails establishing a gene bank for future use.

Usually, individual palms tend to be selected on economic criteria and are chosen from a few well known or easily accessible populations. Sometimes, particularly in the case of disease resistance, it is necessary to sample more widely so as not to miss rare sources of resistance. Due to the wide natural, domestic and agricultural dispersal of the coconut preference is often given to testing of crosses between markedly different phenotypes since this, rather than difference in origins, is the best indicator of deferent genotypes. Recurrent reciprocal selection is often used to produce parents for seed fields and to form the initial population for a new breeding cycle.

Then there is improvement in yield by seed selection and breeding with emphasis on resistance to specific diseases, such as Lethal Yellowing or Cadang-Cadang. In hurricane-prone areas, attention must be given to the need for early bearing and wind resistance. Where, as is so often the case, coconuts are grown by small farmers rather than on plantations, breeders must also take into account the association of the coconut palm with almost every sort. of intercrop. If coconut planting material is to meet the varied requirements of small farmers it must include domestic uses and even ornamental. aspects along with early bearing and high yield.

Many breeding programmes aim at the production and improvement of hybrid planting material so the breeders must improve the base populations of outstanding tall pollen parents through selfings and inter-crossings within and between types. Likewise, other programmes must seek to improve the seed parent, often a dwarf. Some dwarf types, such as the Malayan Dwarf, are already quite good. Others, for example, the Niu leka from the South Pacific, have not yet performed consistently.

In general, modern hybrid breeding programmes seek to identify the best crosses in terms of copra yield by crossing coconuts of different origins. Until recently the emphasis has been placed on dwarf $\mathrm{x}$ tall hybrids to take advantage of the precocity, dwarfness and high frond (hence, bunch) production rate of the dwarf coconut, while the poor copra content and quality of the dwarf would be improved in combination with the tall coconut. Currently, tall $\mathrm{x}$ tall crosses are being considered.

There are certain fairly obvious rules that need to be borne in mind. For instance, exotic and indigenous cultivars, in germplasm bank require evaluation although breeding programmes should not be delayed waiting for those results. Popular varieties can be multiplied and used directly but others may need to be progeny tested first. High yielding mother palms are usually identified for inclusion in the breeding programme. Most genetic improvement programme aim to identify varieties or hybrids which combine high yielding ability with as many as possible of the following characteristics: early bearing, good copra outturn, resistance to pests and diseases and adaptability to varying climatic and management conditions. As well as yield performance trials disease screening trials are also necessary.

Breeding programmes often develop through specific stages. Starting with the exploitation of locally available genetic variability, they give priority to collecting populations having interesting characters, such as; high copra/nut, earliness of bearing, large number of nuts, and adaptability to 
particular environmental conditions. Depending on what is found to be available locally the next step is the introduction of populations of known breeding potential or having one or more interesting characters and their exploitation and conservation. The common practice has been to establish hybrid seed gardens as being the quickest means of improvement. Intercrossing of populations both local and foreign follows, leading to a search for the best cross combination, by conducting comparative hybrid trials. Improvement of the best hybrids is then sought by reciprocal recurrent selection. Once they have been identified the selected parents are multiplied to be able to reproduce, the most interesting hybrids in large quantities. Breeding for pest and disease resistance is usually only considered in areas where problems already exist. Few, if any, examples can be found of undertaking precautionary breeding programmes.

Programmes to improve crop yields and quality through hybridization and selection usually involve mass production of seed of a limited number of hybrid types concurrently with their field evaluation alongside local varieties in a wide range of environments. Some attempts at genetic improvement see prepotency and mother palm seed selection as important factors. Assessment of the performance of new varieties and hybrids must be done on research station trials but also in the hands of small holders.

Breeding programmes, in. general, can be summarized as the study of local varieties, the introduction of exotic germplasm, doing hybridization, running variety trials and organising large scale hybrid seed production.

\section{THOUGHTS ON AIMS AND OBJECTIVES}

\section{THINKING ABOUT YIELD}

It is to be unexpected that the coconut breeding programmes in a number of countries will have a common set of priorities, as summarised above. High yield is the most important. Yield can be expressed in a number of ways. In general terms, the extension officers in the departments of agriculture will be looking for improved crop yield and good copra out-turn. More specifically, the farmer who makes his own copra or sells coconuts to be made into copra, will want high copra production per palm. The copra maker will benefit from high copra content in the nut and the oil-factory manager would like to have a high oil content in the copra. The agricultural economist will call for high oil production to be set against low inputs of time, labour and money. Particular qualities, such as oil with high lauric acid content will be favoured by the industrial chemist or residual meal with high protein and a particular amino acid composition, by the animal nutritionist.

It almost seems as if the coconut breeders have given more attention to yield as a practical agricultural aspect, less to economics; and pratically no attention at all to processing. The varieties they produce tend to require more inputs, not less, whilst high yields achieved experimentally have not been consistently maintained on the farm, if they have been reached at all. There have been suggestions that high yielding varieties have been produced, or found, that do not require high inputs. These claims have not been widely substantiated.

\section{THINKING ABOUT NUT NUMBER \& NUT SIZE}

Individual palms producing large numbers of nuts have always attracted attention but reports of palms bearing more than about 150 nuts per year need to be treated with caution and contrasted with average yields for the surrounding population. Sometimes young, unfertilised button nuts (less than four months old) are included in the count. On other occasions many dry nuts that should have been reaped are included. When single individual palms occur they may be genetically different or they may be growing under particularly favourable localized conditions. In either case it is difficult to use 
single palms or to show what has caused their outstanding performance. (Tissue culture methods, when they are developed may help solve such enigmas). But it is only when the general population has a large number of nuts that practical genetic differences may be involved. Not unexpectedly, large nut number is associated with small nut size. This is so, not only amongst dwarf varieties, but amongst tall varieties as well.

Increased yield in terms of a larger number of nuts tends to be unpopular, perhaps because so much manual labour is involved in harvesting, removing the husk, splitting the nut and picking out the fresh meat or the dry copra, that the desire has been for larger nuts. Perhaps a lesson could be learnt from the oil palm where small individual fruit size has facilitated mechanical processing. The possibility that coconut breeders could increase yield by producing varieties that ease harvesting problems in the field or processing methods such as husk removal and endosperm extraction, seems not to have been considered as long as these jobs are done by hand. Yet there are varieties with many small fruit, that fall. from the palm without the need to be cut-off, which lie on the ground for a longer time without germinating and which even produce ball copra (in the shell) in the dry season.

Nearly all breeding programmes insist that selected palms exceed some predetermined, and above average, annual nut count figure. The actual number chosen may depend on growing conditions as much as on genetic differences. In types where high nut number is genetically determined fruit size tends to be small and this combination of characteristics is almost always considered to be unfavourable. Yet breeding programmes, which may not specifically set increased fruit size as one of the aims because it is taken for granted.

It can be shown, from first principles, that many small nuts give the coconut an evolutionary advantage when it is in its natural, or wild, state. Yet this condition appears to be so rare today that it is usually ignored. Conversely, large fruit size is characteristic of domestication. Characterization of varieties by fruit size is one of the most obvious ways of thinking about a breeding programme but its usefulness has been questioned by those who hope that laboratory techniques with isozymes or polyphenols will be less subjective. The evolutionary reasons for fruit size difference are independent of environment and, unlike the biochemical tests, have already been used across environments. The variability for nut size both within and between populations is not, as may be thought due to conscious selection or genetic drift but is may be due to the introgression of the two contrasting ancestral types without consistent selection, scientific or otherwise.

Fruit size is one of the most obvious and easily recognised differences between varieties and what can be explained for fruit size in phenotypic terms not only reflects real genetic differences but can be expected to apply to other, less easily differentiated characteristics. This has important implications since it helps to explain why straight selection programmes have not been successful and why only certain cross combinations are likely to be successful.

\section{THINKING ABOUT PALM SIZE \& PRECOCITY}

Another factor that increases yield per unit area is the density at which palms can be planted. This is determined, primarily, by the size of the mature palm. As with other perennial tree crops there will be different optimum densities depending upon the age of the palm. When very young a higher density can be tolerated, and makes better use of fertilizer, mutual protection in strong winds. But as the palms grow they will compete for light and tend to etiolate if planted too densely. It is not easy to thin scientifically, nor do farmers like to remove potentially bearing trees. High density will still favour yield at this stage because the overall number of nuts per area will increase even though the number of nuts per palm decrease. 
Most coconut populations are somewhat variable and the growth rates are different. In time the palms crowns take up different portions of the canopy space, much as they do under wild conditions where palms of all ages occur together. If tree crops, and their undercrops and intercrops are seen in three dimensions rather than simply in plan this situation is not necessarily bad. Under plantation conditions it is often felt that palms should be equally spaced, equally aged and equally sized, to make harvesting easier with poles of uniform length (but increasing with age of the palm). But this council of perfection is unrealistic. The concept of purposely planting distinctly different varieties does not seem to have been tried. For instance, a precocious dwarf is removed after the early years of production and as it becomes overshaded by a later bearing, longer lived tall. Or the possibility of canning palm hearts by removing up to three quarters of a densely planted stand at the time they begin to flower.

In dealing with palm size and precocity it is not always clear whether planting density or some other attribute is concerned. For instance, where dwarfs arc used as parents for hybrids the uniformity brought about by a high degree of self pollination is important. The high rate of frond production, and hence bunch production, notable characteristics of the dwarf, arc mentioned, as is precocity. Indeed, early fruit production is a keenly appreciated target. The fact that precocity today can be attributed to modern advances in agronomy, such as polybag nurseries, weed control by herbicide and regular fertilizer application with adequate rates and with major and minor elements properly balanced.

\section{THINKING ABOUT GROWING CONDITIONS}

Coconuts arc most commonly grown on well drained sandy soils of low nutritional and organic matter status where response to adequate fertilization can be excellent. However, the application of fertilizer to coconuts is virtually non existent, except perhaps at the time of planting. The proposal, to select types that will yield well without large fertilizer inputs, is therefore popular, but is it realistic? And if this line of breeding is successful, all those farmers who do not fertilize now will certainly not be persuaded to do so. Instead, they may try to increase yield by planting on soils of first-class natural fertility. Such soils might be better planted with more valuable cash crops except where high rainfall causes erosion. Then coconuts, with cover crops or pasture, would be a better choice.

The coconut is known to grow best where rainfall is high and where soils arc well drained yet it is frequently grown under marginal conditions where droughts occur or where drainage is impeded or where groundwater is saline. It is often grown in the windstorm prone latitudes. It is also grown by every sort of farmer, from industrial plantations at one extreme to subsistence croppers at the other, at every level of efficiency, as a monocrop or as part of a multicropping system. It is unrealistic for any breeding programmes to seek to produce a limited range of varieties or hybrids and expect them to cope with all the varying climatic and management conditions.

\section{THINKING ABOUT PESTS}

For palms, chemical pest control is difficult and expensive. Breeding for pest resistance, in the sense of resistance to leaf eating caterpillars or stem burrowing beetles and weevils seems to be a fairly unlikely option until such advanced methods of incorporating naturally occurring bitter or poisonous chemicals from other plant species has been achieved. And coconut will not be the easiest of plants to do that sort of research. The coconut fruit mite certainly causes more damage on smaller fruited varieties but any reduction in damage seems to be associated with other biological control factors. Fruit sucking insects, such as Pseudotheraptus or Amblypelta might be discouraged if the phenols which occur in the husks of mature fruit developed earlier in the immature buttons. Rats and other rodents which attack the water filled immature fruit may choose the sweeter and easily climbed dwarf varieties first but do not scorn the tall varieties. Nematodes, such as those that cause red ring, or their weevil vectors may find the stern density of some palms less easy to penetrate but this speculation has 
not been proved. This might also apply to the Phytomona flagellate, whilst the possibility that leaf hopper vectors of MLO diseases may not feed or breed on the surviving individuals in those varieties that show a high degree of resistance is worth investigating. Some pest infestations may be avoided or alleviated by growing in crop associations where the coconut varieties are bred to tolerate competition and low levels of infection.

\section{THINKING ABOUT DISEASES}

As with pests, chemical disease control is difficult and expensive. Existing natural resistance is of great importance especially to leaf spot and bud rot caused by fungi. Bacterial infection appears not to be common but virus, viroid, MLO (and RLO) diseases seem to be found wherever pathologist spend enough time looking. In the first place, it should be realised that palm populations are probably tolerant to, if not totally resistant, to many local races of disease. And immune to those diseases of other crops which do not attack coconut at all. Therefore, by sheer chance any breeding programme which does not contain a component for screening for disease resistance, by field exposure, is likely to decrease any natural resistance that does occur. Resistance breeding problems are also much greater with palms than with most other crops. Successful resistance breeding has been demonstrated in the Caribbean but not (yet) emulated in West Africa, East Africa, India or the Philippines where other serious diseases occur. In the (south west) Pacific region viroid diseases of coconut (and oil palm) are a whole new can of worms. It is being suggested that some of the pathogens "discovered" may be present in healthy palms and only seen to become pathogenic when the palm is stressed.

\section{THINKING ABOUT MINOR TARGETS}

Economically the question must be asked, should more attention be given to the minor uses? Over-dependence on copra puts the farmer at the mercy of world market prices over which neither he nor his government have any control. Whereas, the ability to switch to another product, has to be seen as an advantage. In other crops alternative products are not neglected. The soybean is a prime example because when it was. used for oil production rather than for protein it ousted coconut from the position of premier vegetable oil. Coconut breeding prograrnmes have never been aimed at minor uses of the palm such as coir fibre or shell charcoal. These are sometimes considered to be by-products rather than end products in their own right. The same may be said for uses such as desiccated coconut, coconut cream and coconut water. These uses, which compete indirectly with copra production, may be contrasted with the production of sugar or alcohol from coconut sap which competes directly by substantially reducing or even preventing fruit development.

Perhaps when coconut breeders do consider other uses they assume that because a multifarious range of products can be obtained from any one coconut palm that it is a multipurpose plant. This is only true to a limited extent. Wherever the coconut has had a long association with man different sorts are chosen from a highly variable population for different purposes. As an extreme case, the common coconut on the Maldive Islands is the wild type. Generations of boat builders have learnt how to use its curved stern to give the characteristic shape to their boats. They do not welcome domestic (dwarf) and agricultural (hybrid) varieties with a different habit. Plant breeders should consider these minor types, which may have a significance out of all proportion to their number.

It is interesting to note that important research in coconut pathology was carried out in a country where there is no coconut breeding programme and where the coconut is not a crop plant but an ornamental. Where coconut development projects have failed to get hybrids planted by farmers hybrid seed and seed from the dwarf seed parents have been sent to nearby towns or cities to be sold as drinking nuts or for ornamental planting. And in Europe now it is possible to buy coconut seedlings as house plants! So the breeding programme which does mention ornamental factors is not so out of place as it might at first appear. The ISHS Coconut Registration Authority has recently been set up to assist 
in identifying coconut cultivars. Most other registration authorities happen to be on decorative plants; (mango is one exception) but an internationally agreed format for recognising and distinguishing named types is common to crop plants as well and is overdue in coconuts.

\section{THINKING ABOUT MULTIPLE TARGETS}

In suggesting that coconut breeding should be directed at targets other than copra production it must not be overlooked that the breeders are already attempting to achieve multiple targets. For instance, varieties produced with disease resistance must also be acceptable agronomically and varieties that yield well should not be disease susceptible. In many cases however, targets are mutually exclusive. Thus, early germination is desirable in the nursery but not on the palm that is reaped for copra. A seedling that has a high rate of leaf production may not have a large girth at the collar and the young plant that develops a large bole at ground level may not be early bearing. Early bearing varieties may not have the longest life-spans; later bearing sorts have longer, and therefore more expensive, periods of establishment. Large fruited kinds may not carry many fruit; those with a high number may wave small fruit. A large fruit must not contain a high proportion of husk or of water. High oil content and good copra quality may not be found in types producing the greatest amount of copra per nut. All these differences, and more, can be found within the highly variable coconut populations in many countries.

Many selection programmes have been based on the possibility of identifying individual palms that carry all, or most, of the desired characters. Hybridisation programmes tend to look for contrasting parental types that each carry some of the desirable qualities and in which the desirable qualities only are displayed in the hybrid. Yet, there is an even chance that it is the less desirable factors that will show thus a good proportion of hybrid combinations can be expected to be no better than, or even worse than their parents. Three way crosses, which would tend to complicate this simple explanation, have not been widely made or tested to show which parental combinations reinforce each others good qualities and which merely reproduce the widely segregating populations that are common enough anyway.

Good palms, whether arising naturally or produced by controlled pollination procedures, are always a small proportion of any population and it is difficult to raise enough progeny. A successful breeding programme must not only identify, or produce, superior planting material - it must do so in adequate quantities to meet the farmers needs.

\section{THOUGHTS ON BREEDING METHODS}

As has been said before, the techniques of breeding will not be discussed here. Similarly, the genetic arguments in favour of one breeding procedure over another have been discussed elsewhere. This section therefore seeks to explain why the coconut behaves as it does when subjected to different breeding methods.

Coconut breeding programmes, whether considered as long-term or short-term are unlikely to be completed during the career of their originator not, as is often supposed, because of the long generation time and longevity of the palm but, more pragmatically, because of the short-term funding of much agricultural research and greater opportunities for remunerative work elsewhere. Short-term breeding has recently benefited from the ability to produce $\mathrm{F}$, hybrids in large quantities and these programmes are directed towards finding suitable parental types and establishing seed gardens and pollen orchards. The improvement of the parental types, in terms of general or specific combining ability as identified by progeny tests, is part of the long term programme. Both short and long term programmes involve local and foreign germplasm and prospection and collection of foreign types is seen to be desirable because inter-origin crosses are expected to have the greatest potential. 


\section{THINKING ABOUT LOCAL \& FOREIGN GERMPLASM}

The often expressed desire for germplasm collection, which may be called germplasm exchange when one wants to get something for nothing, also reflects the common opinion that the indigenous populations are, highly variable and genetically unimproved. Introductions, it is hoped, will bring desirable traits that are not found in local populations but the means by which desirable sources can be identified in advance depends on the breeder's experience and his intuition. Unavoidably, collections have often to be made in a speculative way and experience is only accumulated as the collection is made or, more often, only after the collection has been planted and observed for some years.

The natural tendency is therefore to collect as much as possible in the hope of including useful material, but to go to those populations which may have already been recognised as promising, usually those in cultivation. There is the strong possibility that unintentional selection pressure will prejudice these sort of collections in favour of certain types, for example large fruit size, at the risk of overlooking others which may be superficially less desirable but inherently more interesting. Collecting germplasm for testing disease resistance is a case in point where the widest possible range must be collected, irrespective of immediate suitability measured in terms of commercial aptitude. This approach also has to be applied to conservation of coconut genetic resources but the logistics of maintaining a living collection of palms are formidable.

\section{THINKING ABOUT INTROGRESSION AS THE CAUSE OF VARIABILITY}

Coconut breeders must know what germplasm they are using but the plant's natural variability has made it difficult to classify. Despite the pan-tropical distribution of coconut the multitude of vernacular names, the limited descriptions and the almost lack of comparable data have obscured what is, in essence, a simple situation.

The differences between coconut populations, and the variability within each population, can be accounted for by the natural evolution of the wild type and its widespread dissemination by floating; the selection for high endosperm content of the domestic type and its distribution by man; the introgression of these two types; the predominance of intermediate recombinant forms; the resegregation of extreme types and the selection of minor variants.

The key to coconut variability is introgression which operates as a major evolutionary factor, particularly where habitats are drastically disturbed by man, and which serves to prevent the formation of stable coconut varieties because each type is able to cross, backcross, sib and self-pollinate so that there is a repeated reassortment of genes at each generation. Even the highly self-pollinating dwarf is not free from contamination although the presence of colour markers makes dwarf populations more uniform. For introgressed tall coconut populations the bulk of the palms will show few of the extreme characteristics of the two basic types but will share, their common characteristics that is those which distinguish a coconut from a cassava or for that matter a chicken. However, a small number of palms in each generation will resemble, more or less closely, one or other of the basic types.

It is often assumed that human selection has caused all the different coconut varieties to appear. This is only true in the sense that selection produced the characteristics of the domestic type, but not individual variants. These arise and may or may not survive through successive generations. Unlike seed corn or rice they are not stored by the human cultivator from one planting season to the next. 
No population is free of the effects of introgression. It is therefore, difficult to recognise the extreme contrasting types. In the Pacific region they tend to be individual palms within fairly small populations. On southeast and south Asian coastlines the coconut populations are larger and although specific types may be common that is the Malayan Dwarf or the San Ramon the wild type is much less visible. In contrast the two types are readily distinguishable in Central America but the differences went unaccounted for many years because the two populations were on different coastlines of the continent and had hardly been grown together.

Should an introgressed population become re-isolated and no longer subject to human interference the wild type characteristics that favour survival in the wild state will become predominant. A return to the absolute extreme type can only be envisaged over a tremendously long, evolutionary time scale.

The domestic type characteristics might be expected to predominate if human selection was continuous. However, the extreme domestic type is no more ideal for copra production than is the extreme wild type. Selection today, therefore, tends to be towards a favourable combination of characters such as thick meat (wild type) and thin husk (domestic type). There are palms in any introgressed population that show favourable recombination but because of the overwhelming number of poorer recombinants the overall yield of the population and of selections from within it will be low.

\section{THINKING ABOUT FITNESS \& ADAPTABILITY}

Fitness implies survival under a certain set of circumstances. Adaptability implies survival irrespective of circumstances. Thus the wild type shows fitness, the domestic type shows adaptability. The introgressed type presumably shows both or neither. The former, if it can be recognised, presumably does very well under some circumstances and well enough under others.

This is just what the plant breeder is after. The latter presumably does not survive.

Fitness is lost under cultivation because this ability to survive is lost. The palm continues in cultivation only as long as it is propagated by the cultivator and protected from predators and competing vegetation. Indeed, under cultivation selection has diverged to produce some types in which nut size is favoured at the expense of nut number (the domestic type carry few, large fruit) and other types in which number is favoured at the expense of size (those dwarf types that have a large number of small fruit). Both these types have lost fitness in contrast to the naturally evolved coconut. That will carry factors for high nut number and factors for large fruit size because both will improve the chances for wide dissemination and successful establishment. Genetically, it seems likely that nut number and size are controlled quantitatively. That is to say that many genes may be involved. All, or most, of these must be retained in the wild type genotype whereas the genotypes of cultivated forms will be depleted by the loss of genes for one factor or another, depending upon the direction and intensity of selection.

It should also be remembered that cultivation is not always a detrimental factor any more than windstorm tolerance and disease resistance would both be encouraged under cultivation (although some may consider that it is cultivation that encourages disease).

\section{THINKING ABOUT COMBINING ABILITY}

Fitness must depend on having the right gene balance, but not necessarily homozygosity (similar genes from both parents). Introgression surely produces heterozygosity (different genes from both parents). These contrasting systems can account for the phenomena of general and specific combining ability (although other factors, must also be involved). 
On the assumption that any sort of domestic, agricultural or scientific selection will tend to concentrate on certain characters. and hence unavoidably on certain gene combinations the effect must be to reduce other gene frequencies. Varieties showing wild type characteristics, will therefore, tend to show good general combining ability with any other form (or even another palm from the same population). It will reintroduce in the progeny those genes that were lost from the other parent as a result of selection, whether natural or artificial. Some wild type genes with additive effect will also tend to augment any that are held in common by both parents but probably not to the extent of accumulating too many unfavourable genes.

In contrast, specific combining ability applies to a cross in which one genotype supplies only those genes that are lacking in the others, again without accumulating unfavourable genes. In effect, crosses that recombine just those complementary and additive characters that are absent. These restore the genetic balance of the resulting progeny and the phenotypic homogeneity of the population. In other words, the individual palms are more fit and the population is more uniform. Here, it might be expected that contrasting palm types are more likely to occur in different origins, hence the success of inter origin crosses.

Varieties that appear to show neither general nor specific combining ability in any or all combinations might be those in which introgression has already produced a functional complement of genes that can neither be augmented nor unbalanced. The fact that the individual palms should themselves be good producers because they already have a favourable gene balance helps account for the often observed fact that crosses between apparently high producing palms do not result in even higher production, but often in lower. The theory of prepotent palms ones can be accepted on the basis of favourable combining ability but the prepotent palms are not themselves superior individual as may be assumed.

\section{THINKING ABOUT RECIPROCAL RECURRENT SELECTION}

Coconut breeding programmes employing reciprocal recurrent selection aim to improve material in which good, or potentially good, combining ability has, bewen identified. This is particularly useful for producing superior strains of the seed and pollen parents required for F, hybrid production. If, as seems to be the case, those parental types need to contrast so as to complement one another then selections should not be convergent. That is to say, neither of the parental lines should be selected to resemble the final recombinant form which the hybridisation programme aims to produce. Rather, selection should be divergent, that is to say it should seek to maintain, reinforce or even increase differences between the parental types.

The extent to which either of the parental forms might resemble the contrasting wild, domestic or introgressed types will. depend on the breeding programme targets. Whatever form is preferred, it must result in planting material that will suit local growing conditions and the uses to which the crop will be put. Needless to say, testing the parents by crossing them at each generation and growing the progeny will continue to be necessary to confirm that the two lines of selection are proceeding satisfactorily and in the required directions.

\section{THINKING ABOUT INTER-ORIGIN CROSSES}

With the knowledge that the variability of most coconut populations can be accounted for by introgression and that the uniformity of other populations by geographical isolation or by selection, it will, be realised that the success of inter-origin crosses will depend on how, and to what extent, the contrasting wild type or domestic type characteristics predominate. The obvious example is the hybrid, Port Bouet 121 (Malayan Dwarf x West African Tall), in which the geographical differences 
correspond to the fortuitous historical isolation of the wild type pollen parent and the limits imposed on introgression by the high degree of self-pollination and the colour markers of the seed parent. The two types could hardly be more different nor their combining abilities more complementary. In contrast the success of the Maypan (Malayan Dwarf x Panama Tall) is not, as might appear due to a wide inter origin cross. The Panama Tall has very many characteristics in common with the Malayan Dwarf because it too originated in Asia and arrived in America only comparatively recently. The reason this cross works is not because of complementary factors for yield but because both parents contribute factors for disease resistance. In fact, the hybrid is only intermediate in resistance to its two parents, but it is better than other dwarf $\mathrm{x}$ tall combinations and, in practice, acceptable.

Populations in which introgression is very marked can no longer be considered as different from each other by reason of geographical distance, any more than can the two, relatively nonintrogressed forms of Central America be grouped together simply because they are "American". After introgression, the exreme wild and domestic types become subordinate types within a variable population. With each generation only the types that meet local conditions will survive. In that way the population adapts and becomes different from, and are preferable to, similar types that are found elsewhere. They might, for example, be more tolerant to local races of disease. For that reason it will be desirable to use local rather than imported material wherever possible. This is not intended to discourage germplasm exchange, which is a necessary and vital adjunct to plant breeding. It means that introductions should be chosen more selectively and with greater precision, to reduce the quarantine risks and to improve the chances of success.

\section{THINKING ABOUT TRUE BREEDING VARIETIES}

Few breeding programmes seem to call for the production of true breeding, high-yielding varieties. This might seem strange since these would avoid the necessity of continually remaking crosses and will overcome the risk of variable progenies being raised by farmers taking seed for planting from dwarf $\mathrm{x}$ tall $\mathrm{F}_{1}$ hybrids. If, as suggested here, fitness is obtained by recombining contrasting types to achieve, true breeding varieties may be impossible to achieve within a practical period of time. Nor would one such variety be expected to adapt to all circumstances. On a commercial basis, it would be impossible to recover the cost of producing a true breeding variety once the first generation comes into production. Tissue culture methods, once they are perfected, may be a way to allow superior palms to be selected and reproduced uniformly, but even then the cost of producing sufficient planting material might still depend on using the cloned plants to produce "clonal" seed by normal $\mathrm{F}_{1}$ hybridisation methods.

\section{THINKING ABOUT VARIETY IDENTIFICATION}

Finally, it is necessary to make a few points about variety identification. There are many names and almost as many descriptions. These have generally prove to be inadequate to distinguish any but the most obvious differences (tall: dwarf habit, big: small fruit, yellow: red: green: brown fruit colours etc.). Some named types have achieved notoriety (San Ramon: Malayan Dwarf: WAT) ; others remain obscure despite having been recognised locally for generations. Real differences in identity are hard to determine when the description is limited to the local name of selected material, the weight of fresh endosperm or copra that it might produce (usually from superior individuals under good growing conditions), a verbal description of the fruit size, shape and colour. The range of variation within any population makes concise description almost impossible. Physical measurements; and photographs are better but it is essential that deferent operators should count, measure and photograph the same parts to a predetermined degree of accuracy and standardisation. There have been some individual and organizational approaches to this but consistency has not been obtained. 
It is hoped that the new ISHS Coconut Registration Authority will stimulate standardisation. Even so these descriptors are still at the mercy of environmental induced differences. Claims have been made that fruit component analysis, pollen isozymes analysis or leaf polyphenol analysis will provide measurements that are accurate, reproducible and above all, diagnostic. In future there may be possibilities for DNA analysis which will relate directly to genotypic differences rather than phenotypic differences. Even so the likely cost and sophistication of such techniques is likely to limit their application and preliminary phenotypic characterisation will still be required. In that case fruit component analysis will be the method of choice.

\section{CONCLUSION}

At the outset it was -suggested that coconut farmers may not have been fully consulted when thinking about the aims and objectives for coconut breeding programmes. This is not to say that coconut farmers have been ignored. All observations made in research fields have been reconsidered when visiting farmer's fields and farmers views have been sought at extension field days and on farm visits. Often, the farmers have volunteered information. But most coconut farmers are small farmers, with the need to earn a living and not much time to give to academic discussions about what the breeder might be able to produce in five, ten or twenty years. At the risk of being taken literally, it might be realistic to suggest that too much hope has been pinned to the breeders' ability to solve the coconut farmers problems with drought tolerant, disease resistant, high yielding varieties. More time and effort is needed to modernise in-field harvesting and on-farm processing if the coconut is to compete with oil palm as a cash crop. It is, and always has been, a superb subsistence crop and, apart perhaps for disease resistance, there is little the breeder can do to improve it in this respect. 